\title{
HIV-2 A-subtype gp125 2 -V3-C3 mutations and their association with CCR5 and CXCR4 tropism
}

\author{
Salvatore Dimonte • Valentina Svicher • \\ Romina Salpini - Francesca Ceccherini-Silberstein • \\ Carlo-Federico Perno $\cdot$ Muhammed Babakir-Mina
}

Received: 11 May 2011 / Accepted: 11 July 2011

(C) Springer-Verlag 2011

\begin{abstract}
The early events of the HIV replication cycle involve the interaction between viral envelope glycoproteins and their cellular CD4-chemokine (CCR5/CXCR4) receptor complex. In this study, for the first time, the HIV-2 A-subtype gp125 2 -V3-C3 mutations and their tropism association were characterized by analyzing 149 HIV-2 sequences from the Los Alamos database. The analysis has strengthened the importance of $\mathrm{C} 2-\mathrm{V} 3-\mathrm{C} 3$ region as a determinant factor for co-receptor selection. Moreover, statistically significant correlations were observed between C2-V3-C3 mutations, and several correlated mutations were associated with CXCR4 and CCR5 co-receptor usage. A dendrogram showed two distinct clusters, with numerous associated mutations grouped, thus dividing CCR5- and CXCR4-tropic viruses. Fourteen X4-tropic virus mutations, all in V3 and C3 domains and forming highly significant subclusters, were found. Finally, R5 associations, two strong subclusters were observed, grouping several C2-V3C3 mutated positions. These data indicate the possible
\end{abstract}

Electronic supplementary material The online version of this article (doi:10.1007/s00705-011-1075-z) contains supplementary material, which is available to authorized users.

S. Dimonte - V. Svicher $\cdot$ R. Salpini .

F. Ceccherini-Silberstein - C.-F. Perno - M. Babakir-Mina ( $\square)$

Virology, Department of Experimental Medicine and

Biochemistry, Tor Vergata University, Via Montpellier 1,

00133 Rome, Italy

e-mail: m.babakir@yahoo.com

C.-F. Perno

National Institute of Infectious Diseases (INMI) 'Lazzaro

Spallanzani', Rome, Italy contribution of $\mathrm{C} 2-\mathrm{V} 3-\mathrm{C} 3$ mutational patterns in regulating HIV-2 tropism.

\section{Introduction}

The occurrence of human immunodeficiency virus type 2 (HIV-2) infection is mainly restricted geographically to West Africa, where the virus was first isolated from patients with AIDS originating from Cape Verde, GuineaBissau and Senegal [1, 2]. Epidemiologic studies have suggested that the incubation period for HIV-2 to the development of disease is longer than for HIV-1 [3] although they are closely related lentiviruses. In addition, HIV-2 is not as easily transmitted perinatally as HIV-1 [4]. Generally, infected patients with HIV-2 have normal CD4 ${ }^{+}$ $\mathrm{T}$ cell counts and low or undetectable plasmatic viral levels $[5,6]$, which is probably related to the slower replication capacity of the virus and a more efficient immune control compared to HIV-1 [5, 7-11]. In line with these phenomena, virus-specific $\mathrm{CD}^{+} \mathrm{T}$ cells in HIV-2-infected individuals preserve a polyfunctional profile comparable to long-term non-progressors (LTNPs) infected with HIV-1 [12].

The observed incidence of HIV-2 infection declined in the years 1990-2000 [13, 14], with infections mostly caused by members of groups A and B. However, in this era of global integration, an increasing number of cases have been recognized in Europe, India, and the United States [15]. Currently, HIV-2 has diversified into eight genetic groups, named $\mathrm{A}$ to $\mathrm{H}$, of which group $\mathrm{A}$ is the most prevalent worldwide [16].

The cellular molecule $\mathrm{CD}^{+}$acts as a receptor for all members of the primate lentivirus group (HIV-1, HIV-2, and a diverse group of SIV strains) and for effective 
infection, these viruses require binding to a chemokine coreceptor, primarily CCR5 or CXCR4 $[17,18]$. The HIV-1 mature envelope (env) glycoproteins gp120 and gp41 constitute a trimeric complex anchored on the virion surface by the viral membrane-spanning segments of gp41 [19-23]. Similarly, in HIV-2, proteolytic digestion by a cellular enzyme(s) converts the polyprotein precursor gp160 to the surface glycoprotein gp125 and transmembrane glycoprotein gp36 cleavage products [24].

The HIV-1 gp120 is retained on the trimer via labile non-covalent interactions with the gp41 ectodomain [25], confers cellular tropism to the virus by binding $\mathrm{CD}^{+}$and a specific co-receptor, and then acts as a trigger for the fusogenic activity of gp41 [26, 27]. The env glycoproteins have extensive $N$-linked glycosylation that shields many conserved epitopes from antibody recognition [28]. The exposed gp120 V3 domain is the main determinant of HIV1 viral tropism and co-receptor interactions [29], and it contains major antigenic and neutralizing epitopes [30, 31].

In spite of the differences in envelope sequences of HIV-1 and HIV-2, they are structurally similar. The CCR5 and CXCR4 appear to be the major co-receptors for HIV-2 [32, 33], while some primary HIV-2 isolates can infect co-receptor-positive cells in the absence of CD4 receptor [34, 35]. Moreover, both membrane-anchored proteins (gp41 and gp36) finally form 6-helix bundles in the $\mathrm{N}$ - and C-terminal regions of the ectodomain [36], which seems to drive fusion and is common to numerous viral and cellular fusion proteins [37].

Although little is known about the role of the HIV-2 env glycoproteins in humoral immunity, it seems that the gp125 V3 region of HIV-2 may contain broadly neutralizing epitopes [38-40]. Paradoxically, it could be concealed within the envelope complex, possibly due to a physical interaction with gp125 C2 and C3 domains [41]. Furthermore, six immunogenic regions have been identified in the HIV-2 envelope glycoproteins. Three of them are in gp125 (amino acids 234 to 248 in C2, 296 to 337 in V3, and 472 to 507 in C5), and the others are in the ectodomain of gp36 (amino acids 573 to 595, 634 to 649, and 644 to 658) [4250]. Recently, Barroso and his co-workers have shown that the HIV-2 C2 and C3 are well exposed in the envelope complex and are under strong diversifying selection [41].

In HIV-2, the net charge of the V3-loop is a determinant of co-receptor selection, like in HIV-1 [51-54].

In the present study, for the first time, we have characterized in terms of co-receptor usage the HIV-2 A-subtype C2-V3-C3 genetic determinants, defining specific related mutations. For this purpose, we analyzed 149 HIV-2 subtype-A env sequences, representing all submitted sequences from viruses for which a single co-receptoruse phenotype has been reported in the Los Alamos database.

\section{Materials and methods}

Sequence analysis

The analysis included 149 HIV-2 subtype-A env sequences, all retrieved from the Los Alamos database (http:// www.hiv.lanl.gov/content/index). Sequences with pure phenotype and/or co-receptor determinations were considered, while dual-mixed viruses were not used. The published env sequence of the HIV-2 ALI strain was used as a reference (GenBank L25445) [55]. Multiple sequence alignments of the gp125 $5_{\mathrm{C} 2-\mathrm{V} 3-\mathrm{C} 3}$ region were performed using ClustalX [56] and were manually edited with the Bioedit software [57].

\section{Statistical analysis}

To analyze C2-V3-C3 mutations, the frequency of all mutations in the 149 HIV-2 sequences was calculated. Fisher exact tests were used to determine whether the differences in frequency between the two groups of samples were statistically significant (sequences with R5 or X4 determination).

The Benjamini-Hochberg method was used to identify results that were statistically significant in multiplehypothesis testing [58]. A false discovery rate of 0.05 was used to determine statistical significance.

To identify significant patterns of pairwise associations between $\mathrm{C} 2-\mathrm{V} 3-\mathrm{C} 3$ mutations, the $\varphi$ coefficient and its statistical significance for each pair of mutations were calculated. A positive and statistically significant correlation between mutations at two specific positions $(0<\varphi<1 ; P<0.05)$ indicates that the latter mutates in a correlated manner in order to confer an advantage in terms of co-receptor selection and that the co-occurrence of these mutations is not due to chance. Moreover, to analyze the covariation structure of mutations in more detail, average linkage hierarchical agglomerative clustering was performed as described elsewhere [59-61]. Mann-Whitney $U$ tests were used to assess statistically significant differences among all the pairwise-associated mutations. Statistical tests were corrected for multiple-hypothesis testing using the Benjamini-Hochberg method at a false discovery rate of 0.05 [58].

\section{Results}

HIV-2 gp125 mutations and their association with tropism

By evaluating the first $\mathrm{C} 2-\mathrm{V} 3-\mathrm{C} 3$ amino acid region in gp125 sequences derived from 149 HIV-2 subtype-A env 
Fig. 1 Frequencies of HIV$2_{\text {C2-v3-C3 }}$ mutations. Frequencies of gp125 C2 (panel "a"), V3 (panel "b") and C3 (panel "c") mutations in HIV-2 R5- (dark grey) and X4-tropic samples (light grey).

Statistically significant differences were assessed by chi-square tests of independence. $P$ values were significant at a false-discovery rate of 0.05 following correction for multiple tests

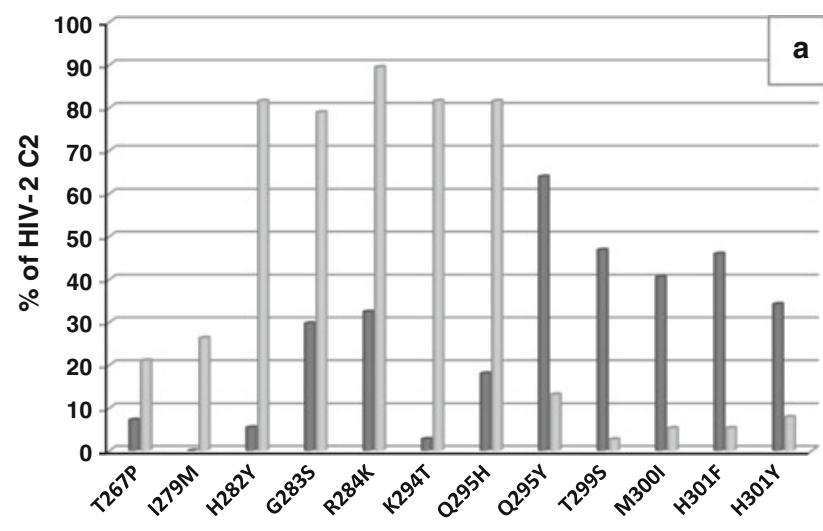

n5 using viruses, $\mathrm{N}=111$

$\mathrm{X} 4$ using viruses, $\mathrm{N}=38$
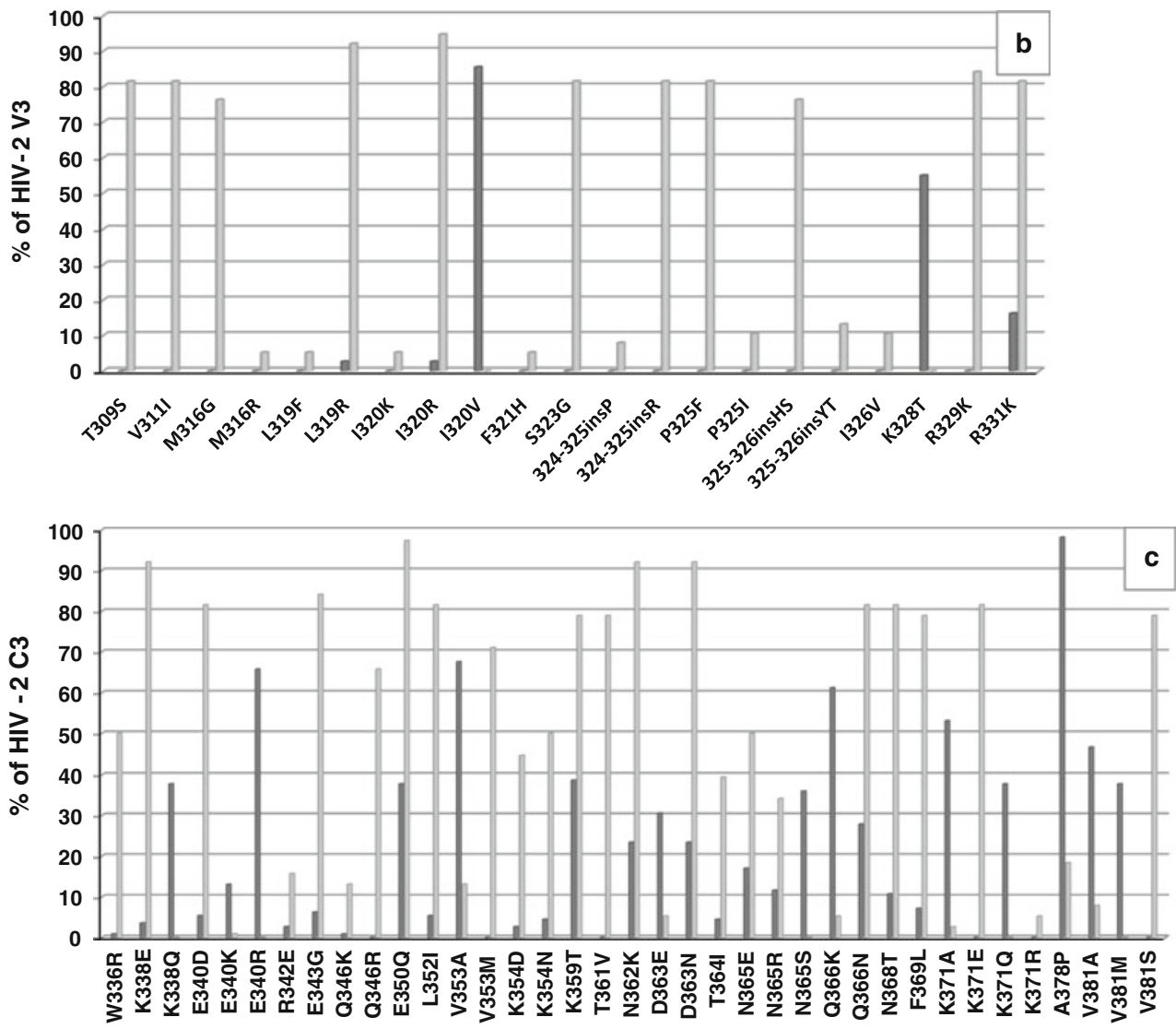

sequences, all retrieved from the Los Alamos database with pure phenotype and/or co-receptor determinations, 111 R5and 38 X4-using co-receptor sequences were selected. Analyzing these two datasets, we identified and characterized 70 gp125 mutations.

In the $\mathrm{C} 2$ domain, 12 out of 36 positions were found to be significantly associated with different co-receptor usage $(P<0.05)$ (Fig. 1a). Five of these mutations (Q295Y, T299S, M300I, H301F and H301Y) had a prevalence that was significantly higher in R5- than in X4-using viruses, all of them with prevalence of $>20 \%$ (Fig. 1a). Conversely, the other 7 mutations (T267P, I279M, H282Y, G283S, R284K, K294T and Q295H) had a prevalence that was significantly higher in X4- than in R5-using viruses, with the prevalence of $>20 \%$ (Fig. 1a).

By analyzing the V3 domain, the I320V and K328T mutations were identified, and their prevalence was significantly higher in the R5- than in the X4-using viruses $(P<0.05)$ (Fig. 1b). Moreover, the prevalence of the 19 V3 mutations was significantly higher in the X4- than in the R5-using viruses $(P<0.05)$ (Fig. 1b). Eleven of them (T309S, V311I, M316G, L319R, I320R, S323G, 324-325insR, P325F, 325-326insHS, R329K and R331K) had a prevalence $>20 \%$ (Fig. 1b).

Finally, in the analysis of the C3 domain, it was found that 22 out of 53 positions were significantly associated 
with different co-receptor usage $(P<0.05)$ (Fig. 1c). Eleven mutations (K338Q, E340R, V353A, D363E, N365S, Q366K, K371A, K371Q, A378P, V381A and $\mathrm{V} 381 \mathrm{M})$ had a prevalence $(>20 \%)$ that was significantly higher in R5- than in $\mathrm{X} 4$-using viruses $(P<0.05)$ (Fig. 1c). In contrast, 22 mutations were identified with a prevalence $>20 \%$ (W336R, K338E, E340D, E343G, Q346R, E350Q, L352I, V353M, K354D, K354N, K359T, T361V, N362K, D363N, T364I, N365E, N365R, Q366N, N368T, F369L, K371E and V381S), and they were significantly higher in $\mathrm{X} 4$ - than in R5-using viruses (Fig. 1c).

Associations among gp125 2 -V3-C3 mutations

Another goal of the present study was to assess the associations of the observed gp125 mutations. To identify significant patterns of pairwise correlations between these observed signatures, the binomial correlation coefficient (phi) and its statistical significance for each pair of mutations were calculated (Table S1). A positive and statistically significant correlation between mutations at two specific positions $(0<\mathrm{phi}<1 ; \mathrm{P}<0.05)$ indicates that these two positions mutate in a correlated manner in order to confer an advantage in terms of specific interactions with a selected co-receptor. This indicates that the co-occurrence of mutations is not due to chance.

The data of this study indicated that some of the HIV-2 gp125 2 -V3-C3 mutations were significantly associated with each other (Table S1). Furthermore, the prevalence of these mutations also depended on the X4 and R5 tropism viruses. For instance, the $\mathrm{K}_{328 \mathrm{~T}_{\mathrm{V} 3}}$ (Fig. 1b) and $\mathrm{E}_{340 \mathrm{R}_{\mathrm{C} 3}}$ (Fig. 1c) mutations were not observed in X4-tropic viruses (Table S1), and similarly, the $\mathrm{Q} 366 \mathrm{~K}_{\mathrm{C} 3}$ and $\mathrm{K}_{371} \mathrm{~A}_{\mathrm{C} 3}$ mutations were retrieved with very low frequency in X4-tropic viruses (Fig. 1c) (Table S1). At the same time, but with significantly high frequency, all of the abovementioned mutations were found in R5-tropic viruses (Fig. 1b and c) (Table S1).

To analyse the covariation structure of the mutations in more detail, we performed an average linkage hierarchical agglomerative clustering, analysing the mutations associated with R5- and X4-tropic viruses. The topology of the dendrogram suggests the existence of two distinct large clusters of mutations involved in HIV-2 CCR5 and CXCR4 co-receptor usage (Fig. 2). In particular, $16 \mathrm{X} 4$-tropic virus

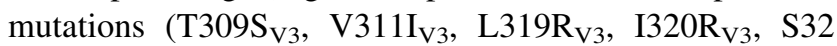
$3 \mathrm{G}_{\mathrm{V} 3}, \quad 324-32$ insR $_{\mathrm{V} 3}, \quad \mathrm{P} 325 \mathrm{~F}_{\mathrm{V} 3}, \quad 325-326$ insHS $_{\mathrm{V} 3}, \mathrm{R} 32$ $9 \mathrm{~K}_{\mathrm{V} 3}, \mathrm{R} 331 \mathrm{~K}_{\mathrm{V} 3}, \mathrm{~K} 338 \mathrm{E}_{\mathrm{C} 3}, \mathrm{Q} 346 \mathrm{R}_{\mathrm{C} 3}, \mathrm{~V}_{3} 33 \mathrm{M}_{\mathrm{C} 3}, \mathrm{~T} 361 \mathrm{~V}_{\mathrm{C} 3}$, $\mathrm{Q} 366 \mathrm{~N}_{\mathrm{C} 3}$ and $\mathrm{K} 371 \mathrm{E}_{\mathrm{C} 3}$ ) were formed two very strong and highly significant sub-clusters (bootstrap values: 0.99 and 0.62 , respectively), and they contained many V3 and C3 signatures (Fig. 2).
At the same time, two very strong sub-clusters were also observed for R5 associations (bootstrap value $=1$ for both) in which several $\mathrm{C} 2, \mathrm{~V} 3$ and $\mathrm{C} 3$ mutated positions $\left(\mathrm{M}_{300 \mathrm{I}_{\mathrm{C}} \text {, }}\right.$

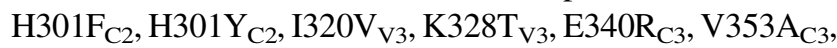

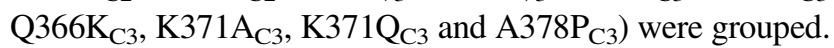

\section{Discussion}

A bioinformatic characterization of co-receptor usage of HIV-2 was done by studying the $\mathrm{C} 2-\mathrm{V} 3-\mathrm{C} 3$ regions of the viral surface protein gp125. Additional specific genetic viral determinants and their association with CCR5 or CXCR4 co-receptor usage were found among 149 HIV-2 subtype-A env sequences.

In the $\mathrm{C} 2$ domain, which is composed of 36 amino acid residues, 12 positions were found to be significantly associated with different co-receptor usage $(P<0.05)$ (Fig. 1a). In particular, five mutations had a prevalence $(>20 \%)$ that was significantly higher in R5- than in X4using viruses (Fig. 1a), suggesting an association of these mutations with CCR5 usage. In contrast, the prevalence of the other seven mutations ( $>20 \%)$ was significantly higher in X4- than in R5-using viruses (Fig. 1a), suggesting their association with the CXCR4-usage.

In the analysis of the V3 domain, two mutations (I320V and $\mathrm{K} 328 \mathrm{~T}$ ) were found to have a prevalence of $>20 \%$ and were significantly more frequent in R5- than in X4-using viruses $(P<0.05)$. These results suggest their association with CCR5 usage (Fig. 1b). Furthermore, 11 V3 mutations were identified. They had a prevalence that was significantly higher in the $\mathrm{X} 4$ - than in the R5-using viruses $(P<0.05$, prevalence $>20 \%)$, suggesting that, within the $\mathrm{V} 3$ region, more mutations are associated with CXCR4 than CCR5 usage (Fig. 1b).

Interestingly, some V3 mutations have also recently been shown to be associated with co-receptor usage [62]. The authors reported that the I320KR, R329K, R331K mutations and insertions at position 325 were associated with dual/X4 tropism, while in our study, an association with the pure CXCR4 co-receptor was observed.

Moreover, Barroso and co-workers, using computer modeling simulations, have shown that amino acid positions 319,320 and $328 \mathrm{HIV}-2$ gp125 $5_{\mathrm{V} 3}$ are potentially involved in co-receptor binding [41]. According to our results, a high variability in these positions in X4-tropic viruses was found (Fig. 1b). This observation was moderately surprising, because a stronger positive selection at several HIV-2 sites compared to those of HIV-1 has already been shown [41], although the V3 heterogeneity of HIV-1 is a specific characteristic that occurs in the viral population of infected individuals (for example, making it practical in co-receptor selection) [63-66]. 


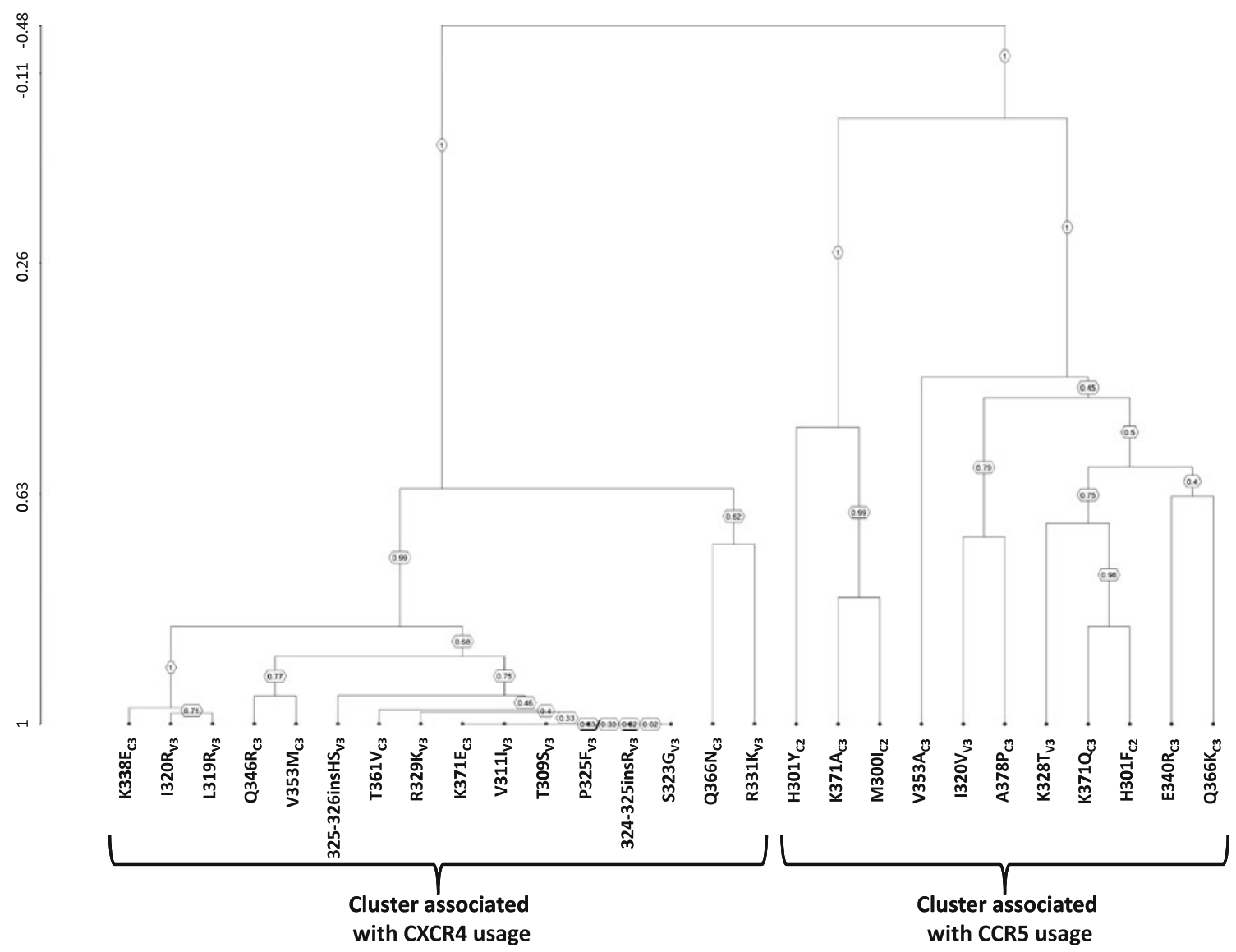

Fig. 2 Clusters of correlated mutations. Dendrogram obtained from average linkage hierarchical agglomerative clustering, showing significant clusters involving gp $125_{\mathrm{C} 2-\mathrm{V} 3-\mathrm{C} 3}$ mutations. The lengths of branches reflect distances between mutations in the original distance matrix. Boostrap values, indicating the significance of clusters, are

Moreover, by analyzing the $\mathrm{C} 3$ domain, 22 out of 53 positions were significantly associated with different coreceptor usage $(P<0.05)$ (Fig. 1c). The prevalence of 11 mutations was significantly higher in R5-using than in X4using viruses, and all of them had a prevalence of $>20 \%$ (Fig. 1c). In contrast, the other 22 mutations had a prevalence $>20 \%$ which was significantly higher in X4- than in R5-viruses, suggesting their association with the CXCR4 usage (Fig. 1c).

At the end of the $\mathrm{C} 3$ domain, the sequence between amino acids 377-388 could contribute to the formation of the CD4-binding site [41]. In our analysis, the A378 and V381 positions were highly variable (Fig. 1c). The high solvent accessibility of this region (residues 377-388), the high variability of amino acid residue A378 under positive selection [41], and the high conservation of the region (residues 377-388) in both viral tropic categories observed in our study (10/12 amino acids) consistently support the idea that this specific $\mathrm{C} 3$ subdomain plays a role in the interactions with the cellular receptor CD4. shown in boxes. The analysis was performed with sequences derived from 149 samples, 111 of which were reported to be R5-tropic and 38 of which were X4-tropic, all with the phenotypic determination based on a recombinant virus entry assay on $\mathrm{U} 87-\mathrm{CD} 4^{+}{ }_{-\mathrm{CCR}} 5^{+}-\mathrm{CXCR}^{+}{ }_{-}$ expressing cells

Recently, computer modeling simulations have shown that, in HIV-2, the non-covalent interactions between W334 in V3 involve residue $\mathrm{H} 301$ in $\mathrm{C} 2$ [41]. In our dataset, a variability of $\mathrm{H} 301$, especially in R5-tropic viruses, was observed ( $\mathrm{H} 301 \mathrm{~F}$ and $\mathrm{H} 301 \mathrm{Y}$, with $40.5 \%$ and $45.9 \%$ prevalence, respectively), while the tryptophan at the end of the V3 domain was fully conserved in all 149 sequences analyzed (100\% prevalence). Probably, the basic amino acid substitution at position 301 with aromatic residues was not detrimental in these complex structural interactions. Actually, the non-covalent interactions between Y296 and H301 in C2/V3 composed a protein relation pathway with R331-W334 in V3, and with F321F337 in V3/C3 [41]. At the same time, a mutation only in R5-tropic viruses at position 337 (F337L) in the $\mathrm{C} 3$ domain was observed in three samples $(2.7 \%)$. This substitution of leucine for phenylalanine could primarily perturb the regions surrounding the amino acids that contact residue 337 in the wild-type glycoprotein. This is probably the best interpretation of the low variability. 
A comparison of diversifying selection between terminal and internal branches of the phylogenetic trees between C2-V3-C3 HIV-1 and HIV-2 sequences has revealed two distinct profiles. This suggests that natural selection affects the transmission fitness of HIV-1 less than that of HIV-2 [41]. Moreover, these observations were also found in our study, with the presence of non-conservative amino acid substitutions (i.e., T267P, P325F, W336R).

Because pairwise analysis suggested that most mutations were associated, we performed average linkage hierarchical agglomerative cluster analysis [59-61] to investigate this hypothesis in more detail. By using this analytical method, we found for the first time specific and statistically significant correlations between C2, V3 and C3 mutations. In particular, several correlated mutations were associated with the CXCR4 and CCR5 phenotype usage (Fig. 2). This is in agreement with the interactions between C2, V3 and C3 domains in HIV-2 gp125 [41].

The dendrogram in Fig. 2 shows two distinct and wellseparated clusters (bootstrap value $=1$ for both) with several associated mutations grouped, dividing the CCR5and CXCR4-co-receptor-tropic viruses. Fourteen X4-tropic virus mutations $\left(^{T} 309 \mathrm{~S}_{\mathrm{V} 3}, \mathrm{~V} 311 \mathrm{I}_{\mathrm{V} 3}, \mathrm{~L}_{3} 19 \mathrm{R}_{\mathrm{V} 3}, \mathrm{I}_{2} 20 \mathrm{R}_{\mathrm{V} 3}\right.$, $\mathrm{S}_{2} 23 \mathrm{G}_{\mathrm{V} 3}, 324-325$ insR $_{\mathrm{V} 3}, \mathrm{P}_{325 F_{\mathrm{V} 3}}, 325-326$ insHS $_{\mathrm{V} 3}, \mathrm{R} 32$ $9 \mathrm{~K}_{\mathrm{V} 3}, \mathrm{~K} 338 \mathrm{E}_{\mathrm{C} 3}, \quad \mathrm{Q} 346 \mathrm{R}_{\mathrm{C} 3}, \mathrm{~V} 353 \mathrm{M}_{\mathrm{C} 3}, \mathrm{~T} 361 \mathrm{~V}_{\mathrm{C} 3}$ and

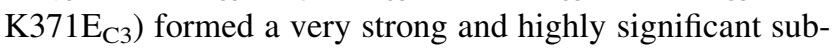
cluster (bootstrap value $=0.99$ ). Some of these mutations, like the associated positions 319, 320, 323 and 338, have been observed previously [40, 50]. Specifically, recombinant polypeptides representing the gp125 (rpC2-C3) in infected patients, Marcelino and colleagues did not detect reactive $\mathrm{IgG}$ antibodies [50]. Similar results were observed with $\mathrm{X} 4$-tropic viruses that were resistant to neutralization in a vaccinia virus vector-prime/rpC2-C3-polypeptideboost vaccination strategy [40]. In the first study, the authors examined nonspecific and Env-specific IgA and IgG responses in acute and chronic HIV-2 infection [50], while in the other work, the same team used a mouse model to investigate the immunogenicity and neutralizing response elicited when a recombinant HIV-2 envelope proteins was administered [40].

A first essential description was for the two V3 subsequent mutated positions, L319R and I320R, which, interestingly, form a very strong $\mathrm{X} 4$ sub-cluster with the K338E mutation located in the $\mathrm{C} 3$ domain $\left(\mathrm{P}=2.9 \mathrm{e}^{-32}\right.$; $\varphi=0.98$; and $\mathrm{P}=2.3 \mathrm{e}^{-31} ; \varphi=0.97$ ) (Fig. 2; Table S1). In an interesting study, Shi and colleagues have observed in a four-PBMC-passage stock the conservation of $\mathrm{L}_{319 \mathrm{R}_{\mathrm{V} 3} \text {, }}$, $\mathrm{I}_{320 \mathrm{R}_{\mathrm{V} 3}}$ and $\mathrm{K} 338 \mathrm{E}_{\mathrm{C} 3}$ mutations in viral isolates that efficiently use CXCR4 [54]. Probably, V3 and C3 interaction at these positions, which flank the amino acids $\mathrm{F} 337_{\mathrm{C} 3}$ and $\mathrm{F} 321_{\mathrm{V} 3}$, which are already involved in the predicted non-covalent interaction [41].
Secondly, we noted that numerous positions located in the V3 core correlated with $\mathrm{Q} 346 \mathrm{R}_{\mathrm{C} 3}, \mathrm{~V} 353 \mathrm{M}_{\mathrm{C} 3}$ and $\mathrm{K} 371 \mathrm{E}_{\mathrm{C} 3}$ substitutions and with a mutation under positive selection, T361 $\mathrm{V}_{\mathrm{C} 3}$ [41] (Fig. 2; Table $\mathrm{S} 1$ ). Besides, some V3 signatures related to the CXCR4 co-receptor, such as R329K and the insertions at position 325 (Fig. 2), have been shown to be molecular determinants of HIV-2 X4/ dual tropic viruses [62]. The exact classification of linkage of these listed mutations was associated with reduced bootstrap values, probably due to the considerable flexibility in their order of accumulation (Fig. 2).

Finally, there is no clear explanation for the small flanking cluster formed by $\mathrm{R} 331 \mathrm{~K}_{\mathrm{V} 3}$ and $\mathrm{Q} 366 \mathrm{~N}_{\mathrm{C} 3}$ $\left(\mathrm{P}=1.5 \mathrm{e}^{-18} ; \varphi=0.71\right)$ (Table $\left.\mathrm{S} 1\right)$. These two positions were not neighbors in the predicted conformational C2-V3$\mathrm{C} 3$ structure [41]. On the other hand, the $\mathrm{Q} 366 \mathrm{~N}_{\mathrm{C} 3}$ mutation was present in one of two patients in which $\operatorname{IgG}$ antibodies were not detected [50] and in several X4-tropic viruses that were resistant to neutralization by vaccination [40]. Effectively, this last position could play a supporting role in co-receptor interaction and was possibly also observed in an R5 cluster (Fig. 2).

For R5 associations, two very strong subclusters were found (bootstrap value $=1$ for both), grouping several C2, V3 and C3 mutated positions. Interestingly, in the larger

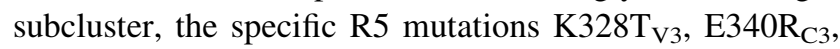
$\mathrm{V} 353 \mathrm{~A}_{\mathrm{C} 3}$ and the abovementioned $\mathrm{Q} 366 \mathrm{~K}_{\mathrm{C} 3}$, were detected (Fig. 2, Table S1). Coherently, these signatures were already observed in different primary R5 HIV-2 group A isolate [40]. Furthermore, we show the presence of position I320 ${ }_{\mathrm{V} 3}$, which characterizes the R5 cluster with a valine mutation, a signature that is robustly associated with the A378 $\mathrm{P}_{\mathrm{C} 3}$ mutation $\left(\mathrm{P}=8.27 \mathrm{e}^{-18} ; \varphi=0.70\right.$, bootstrap $=$ 0.79). Moreover, a clustering of $\mathrm{K}_{3} 38 \mathrm{~T}_{\mathrm{V} 3}$ with $\mathrm{H} 301 \mathrm{~F}_{\mathrm{C} 2}$ $\left(\mathrm{P}=3.96 \mathrm{e}^{-7} ; \varphi=0.41\right)$ and with $\mathrm{K} 371 \mathrm{Q}_{\mathrm{C} 3}\left(\mathrm{P}=3.09 \mathrm{e}^{-10}\right.$; $\varphi=0.47) \quad$ (bootstrap $=0.75) \quad$ was observed (Fig. 2; Table 1). This result indicates that R5-tropic viruses may have several C2, V3 and C3 mutated positions.

The previous observation suggests that only a few amino acid differences are critically important for co-receptor usage of HIV-2, especially in the C-terminal half of the V3-loop region [67]. In contrast, our analysis confirmed the importance of the $\mathrm{C} 2-\mathrm{V} 3-\mathrm{C} 3$ region as a determinant of coreceptor selection. This information was deduced indirectly from HIV-2 isolates obtained from asymptomatic individuals that do not use CCR5 or CXCR4 co-receptors to infect primary peripheral blood mononuclear cells (PBMCs) [67]. Some studies have shown notable differences particularly in the V1/V2 and C5 regions of gp125 in the CCR5/ CXCR4-independent HIV-2 viruses [68, 69].

In conclusion, our study further demonstrates the complexity of HIV-2 co-receptor selection and contributes to a better definition the $\mathrm{C} 2-\mathrm{V} 3-\mathrm{C} 3$ mutational patterns 
involved in regulating tropism. It suggests that other mutations beyond those currently known to confer CCR5 or CXCR4 usage may regulate this highly complex network. The models proposed to explain the mechanisms of action of these mutational patterns suggest and support the interaction between these gp125 domains. This highlights the importance of the correct interplay between the different regions of the protein, and on this basis, novel signatures should be taken into account for predicting genotypic tropism or the biology of interactions of HIV-2 with cells.

Acknowledgments This work was financially supported by grants from the Italian Ministry of Instruction University \& Research (MIUR), "Progetto FILAS", and by the European Commission Framework 7 Programme (CHAIN, the Collaborative HIV and AntiHIV Drug Resistance Network, Integrated Project no. 223131). We are thankful for Amalia Mastrofrancesco, Marzia Romani and Fabio Mercurio for their excellent technical assistance.

\section{References}

1. Barin F, Goudeau A, Romet-Lemonne JL, Choutet P, Chassaigne M (1985) Virus carriage in symptom-free blood donor positive for HTLV-III antibody. Lancet 2:98

2. Clavel F, Guetard D, Brun-Vezinet F, Chamaret S, Rey MA, Santos-Ferreira MO, Laurent AG, Dauguet C, Katlama C, Rouzioux C (1986) Isolation of a new human retrovirus from West African patients with AIDS. Science 233:343-346

3. Pepin J, Morgan G, Dunn D, Gevao S, Mendy M, Gaye I, Scollen N, Tedder R, Whittle H (1991) HIV-2-induced immunosuppression among asymptomatic West African prostitutes: evidence that HIV-2 is pathogenic, but less so than HIV-1. AIDS 5:1165-1172

4. Markovitz DM (1993) Infection with the human immunodeficiency virus type 2. Ann Intern Med 118:211-218

5. Berry N, Ariyoshi K, Jaffar S, Sabally S, Corrah T, Tedder R, Whittle H (1998) Low peripheral blood viral HIV-2 RNA in individuals with high CD4 percentage differentiates HIV-2 from HIV-1 infection. J Hum Virol 1:457-468

6. Soares R, Foxall R, Albuquerque A, Cortesao C, Garcia M, Victorino RM, Sousa AE (2006) Increased frequency of circulating CCR5+ CD4+ $\mathrm{T}$ cells in human immunodeficiency virus type 2 infection. J Virol 80:12425-12429

7. Anderson DE, Llenado RA, Torres JV (2004) Humoral immunity and the evolution of HIV-2. Viral Immunol 17:436-439

8. Berry N, Jaffar S, Schim van der Loeff M, Ariyoshi K, Harding E, N'Gom PT, Dias F, Wilkins A, Ricard D, Aaby P, Tedder R, Whittle H (2002) Low level viremia and high CD4\% predict normal survival in a cohort of HIV type-2-infected villagers. AIDS Res Hum Retrovirus 18:1167-1173

9. MacNeil A, Sarr AD, Sankale JL, Meloni ST, Mboup S, Kanki P (2007) Direct evidence of lower viral replication rates in vivo in human immunodeficiency virus type 2 (HIV-2) infection than in HIV-1 infection. J Virol 81:5325-5330

10. Lizeng Q, Nilsson C, Sourial S, Andersson S, Larsen O, Aaby P, Ehnlund M, Bjorling E (2004) Potent neutralizing serum immunoglobulin A (IgA) in human immunodeficiency virus type 2-exposed IgG-seronegative individuals. J Virol 78:7016-7022

11. Blaak H, Brouwer M, Ran LJ, de Wolf F, Schuitemaker H (1998) In vitro replication kinetics of human immunodeficiency virus type 1 (HIV-1) variants in relation to virus load in long-term survivors of HIV-1 infection. J Infect Dis 177:600-610

12. Duvall MG, Precopio ML, Ambrozak DA, Jaye A, McMichael AJ, Whittle HC, Roederer M, Rowland-Jones SL, Koup RA (2008) Polyfunctional T cell responses are a hallmark of HIV-2 infection. Eur J Immunol 38:350-363

13. Hamel DJ, Sankale JL, Eisen G, Meloni ST, Mullins C, GueyeNdiaye A, Mboup S, Kanki PJ (2007) Twenty years of prospective molecular epidemiology in Senegal: changes in HIV diversity. AIDS Res Hum Retrovirus 23:1189-1196

14. van der Loeff MF, Awasana AA, Sarge-Njie R, van der Sande M, Jaye A, Sabally S, Corrah T, McConkey SJ, Whittle HC (2006) Sixteen years of HIV surveillance in a West African research clinic reveals divergent epidemic trends of HIV-1 and HIV-2. Int J Epidemiol 35:1322-1328

15. Campbell-Yesufu OT, Gandhi RT (2011) Update on human immunodeficiency virus (HIV)-2 infection. Clin Infect Dis 52: 780-787

16. Rowland-Jones S (2006) Protective immunity against HIV infection: lessons from HIV-2 infection. Futur Microbiol 1:427-433

17. Hoxie JA, Haggarty BS, Bonser SE, Rackowski JL, Shan H, Kanki PJ (1988) Biological characterization of a simian immunodeficiency virus-like retrovirus (HTLV-IV): evidence for CD4-associated molecules required for infection. J Virol 62: 2557-2568

18. Sattentau QJ, Clapham PR, Weiss RA, Beverley PC, Montagnier L, Alhalabi MF, Gluckmann JC, Klatzmann D (1988) The human and simian immunodeficiency viruses HIV-1, HIV-2 and SIV interact with similar epitopes on their cellular receptor, the CD4 molecule. AIDS 2:101-105

19. Chan DC, Fass D, Berger JM, Kim PS (1997) Core structure of gp41 from the HIV envelope glycoprotein. Cell 89:263-273

20. Weissenhorn W, Dessen A, Harrison SC, Skehel JJ, Wiley DC (1997) Atomic structure of the ectodomain from HIV-1 gp41. Nature 387:426-430

21. Farzan M, Choe H, Desjardins E, Sun Y, Kuhn J, Cao J, Archambault D, Kolchinsky P, Koch M, Wyatt R, Sodroski J (1998) Stabilization of human immunodeficiency virus type 1 envelope glycoprotein trimers by disulfide bonds introduced into the gp41 glycoprotein ectodomain. J Virol 72:7620-7625

22. Zhu P, Chertova E, Bess J Jr, Lifson JD, Arthur LO, Liu J, Taylor KA, Roux KH (2003) Electron tomography analysis of envelope glycoprotein trimers on HIV and simian immunodeficiency virus virions. Proc Natl Acad Sci USA 100:15812-15817

23. Wyatt R, Sodroski J (1998) The HIV-1 envelope glycoproteins: fusogens, antigens, and immunogens. Science 280:1884-1888

24. Jadhav S, Tripathy S, Kulkarni S, Chaturbhuj D, Ghare R, Bhattacharya J, Paranjape R (2011) Genetic conservation in gp36 transmembrane sequences of Indian HIV type 2 isolates. AIDS Res Hum Retrovirus

25. Helseth E, Olshevsky U, Furman C, Sodroski J (1991) Human immunodeficiency virus type 1 gp120 envelope glycoprotein regions important for association with the gp41 transmembrane glycoprotein. J Virol 65:2119-2123

26. Dragic T, Litwin V, Allaway GP, Martin SR, Huang Y, Nagashima KA, Cayanan C, Maddon PJ, Koup RA, Moore JP, Paxton WA (1996) HIV-1 entry into CD4+ cells is mediated by the chemokine receptor CC-CKR-5. Nature 381:667-673

27. Eckert DM, Kim PS (2001) Mechanisms of viral membrane fusion and its inhibition. Annu Rev Biochem 70:777-810

28. Wyatt R, Kwong PD, Desjardins E, Sweet RW, Robinson J, Hendrickson WA, Sodroski JG (1998) The antigenic structure of the HIV gp120 envelope glycoprotein. Nature 393:705-711

29. Hwang SS, Boyle TJ, Lyerly HK, Cullen BR (1991) Identification of the envelope V3 loop as the primary determinant of cell tropism in HIV-1. Science 253:71-74 
30. Krachmarov CP, Honnen WJ, Kayman SC, Gorny MK, ZollaPazner S, Pinter A (2006) Factors determining the breadth and potency of neutralization by $\mathrm{V} 3$-specific human monoclonal antibodies derived from subjects infected with clade A or clade B strains of human immunodeficiency virus type 1. J Virol 80:7127-7135

31. Forsell MN, Schief WR, Wyatt RT (2009) Immunogenicity of HIV-1 envelope glycoprotein oligomers. Curr Opin HIV AIDS 4:380-387

32. Blaak H, Boers PH, Gruters RA, Schuitemaker H, van der Ende ME, Osterhaus AD (2005) CCR5, GPR15, and CXCR6 are major coreceptors of human immunodeficiency virus type 2 variants isolated from individuals with and without plasma viremia. J Virol 79:1686-1700

33. Morner A, Bjorndal A, Leandersson AC, Albert J, Bjorling E, Jansson M (2002) CCR5 or CXCR4 is required for efficient infection of peripheral blood mononuclear cells by promiscuous human immunodeficiency virus type 2 primary isolates. AIDS Res Hum Retrovirus 18:193-200

34. Clapham PR, McKnight A, Weiss RA (1992) Human immunodeficiency virus type 2 infection and fusion of CD4-negative human cell lines: induction and enhancement by soluble CD4. J Virol 66:3531-3537

35. Reeves JD, Hibbitts S, Simmons G, McKnight A, AzevedoPereira JM, Moniz-Pereira J, Clapham PR (1999) Primary human immunodeficiency virus type 2 (HIV-2) isolates infect CD4negative cells via CCR5 and CXCR4: comparison with HIV-1 and simian immunodeficiency virus and relevance to cell tropism in vivo. J Virol 73:7795-7804

36. Gallo SA, Sackett K, Rawat SS, Shai Y, Blumenthal R (2004) The stability of the intact envelope glycoproteins is a major determinant of sensitivity of HIV/SIV to peptidic fusion inhibitors. J Mol Biol 340:9-14

37. Blumenthal R, Clague MJ, Durell SR, Epand RM (2003) Membrane fusion. Chem Rev 103:53-69

38. Bjorling E, Chiodi F, Utter G, Norrby E (1994) Two neutralizing domains in the $\mathrm{V} 3$ region in the envelope glycoprotein gp125 of HIV type 2. J Immunol 152:1952-1959

39. Morner A, Achour A, Norin M, Thorstensson R, Bjorling E (1999) Fine characterization of a V3-region neutralizing epitope in human immunodeficiency virus type 2. Virus Res 59:49-60

40. Marcelino JM, Borrego P, Rocha C, Barroso H, Quintas A, Novo C, Taveira N (2010) Potent and broadly reactive HIV-2 neutralizing antibodies elicited by a vaccinia virus vector prime-C2 $23 \mathrm{C} 3$ polypeptide boost immunization strategy. J Virol 84:12429-12436

41. Barroso H, Borrego P, Bartolo I, Marcelino JM, Familia C, Quintas A, Taveira N (2011) Evolutionary and structural features of the $\mathrm{C} 2, \mathrm{~V} 3$ and $\mathrm{C} 3$ envelope regions underlying the differences in HIV-1 and HIV-2 biology and infection. PLoS ONE 6:e14548

42. de Wolf F, Meloen RH, Bakker M, Barin F, Goudsmit J (1991) Characterization of human antibody-binding sites on the external envelope of human immunodeficiency virus type 2. J Gen Virol 72(Pt 6):1261-1267

43. Gnann JW Jr, McCormick JB, Mitchell S, Nelson JA, Oldstone MB (1987) Synthetic peptide immunoassay distinguishes HIV type 1 and HIV type 2 infections. Science 237:1346-1349

44. Huang ML, Essex M, Lee TH (1991) Localization of immunogenic domains in the human immunodeficiency virus type 2 envelope. J Virol 65:5073-5079

45. Lizeng Q, Skott P, Sourial S, Nilsson C, Andersson SS, Ehnlund M, Taveira N, Bjorling E (2003) Serum immunoglobulin A (IgA)-mediated immunity in human immunodeficiency virus type 2 (HIV-2) infection. Virology 308:225-232

46. Mannervik M, Putkonen P, Ruden U, Kent KA, Norrby E, Wahren B, Broliden PA (1992) Identification of B-cell antigenic sites on HIV-2 gp125. J Acquir Immune Defic Syndr 5:177-187
47. Norrby E, Putkonen P, Bottiger B, Utter G, Biberfeld G (1991) Comparison of linear antigenic sites in the envelope proteins of human immunodeficiency virus (HIV) type 2 and type 1 . AIDS Res Hum Retrovirus 7:279-285

48. Schulz TF, Oberhuber W, Hofbauer JM, Hengster P, Larcher C, Gurtler LC, Tedder R, Wachter H, Dierich MP (1989) Recombinant peptides derived from the env-gene of HIV-2 in the serodiagnosis of HIV-2 infections. AIDS 3:165-172

49. Zuber M, Samuel KP, Lautenberger JA, Kanki PJ, Papas TS (1990) Bacterially produced HIV-2 env polypeptides specific for distinguishing HIV-2 from HIV-1 infections. AIDS Res Hum Retrovirus 6:525-534

50. Marcelino JM, Nilsson C, Barroso H, Gomes $\mathrm{P}$, Borrego $\mathrm{P}$, Maltez F, Rosado L, Doroana M, Antunes F, Taveira N (2008) Envelope-specific antibody response in HIV-2 infection: C2V3C3-specific IgG response is associated with disease progression. AIDS 22:2257-2265

51. Fouchier RA, Groenink M, Kootstra NA, Tersmette M, Huisman HG, Miedema F, Schuitemaker H (1992) Phenotype-associated sequence variation in the third variable domain of the human immunodeficiency virus type 1 gp120 molecule. J Virol 66:3183-3187

52. Nabatov AA, Pollakis G, Linnemann T, Kliphius A, Chalaby MI, Paxton WA (2004) Intrapatient alterations in the human immunodeficiency virus type 1 gp120 V1V2 and V3 regions differentially modulate coreceptor usage, virus inhibition by $\mathrm{CC} / \mathrm{CXC}$ chemokines, soluble CD4, and the b12 and 2G12 monoclonal antibodies. J Virol 78:524-530

53. Pollakis G, Kang S, Kliphuis A, Chalaby MI, Goudsmit J, Paxton WA (2001) N-linked glycosylation of the HIV type-1 gp120 envelope glycoprotein as a major determinant of CCR5 and CXCR4 coreceptor utilization. J Biol Chem 276:13433-13441

54. Shi Y, Brandin E, Vincic E, Jansson M, Blaxhult A, Gyllensten K, Moberg L, Brostrom C, Fenyo EM, Albert J (2005) Evolution of human immunodeficiency virus type 2 coreceptor usage, autologous neutralization, envelope sequence and glycosylation. J Gen Virol 86:3385-3396

55. Taveira NC, Bex F, Burny A, Robertson D, Ferreira MO, MonizPereira J (1994) Molecular characterization of the env gene from a non-syncytium-inducing HIV-2 isolate (HIV-2ALI). AIDS Res Hum Retrovirus 10:223-224

56. Thompson JD, Gibson TJ, Plewniak F, Jeanmougin F, Higgins DG (1997) The CLUSTAL_X windows interface: flexible strategies for multiple sequence alignment aided by quality analysis tools. Nucleic Acids Res 25:4876-4882

57. Hall TA (1979) BioEdit: a user-friendly biological sequence alignment editor and analysis program for Windows 95/98/NT. Nucl Acids Symp Ser 41:95-98

58. Benjamini Y, Hochberg Y (1995) Controlling the false discovery rate: a practical and powerful approach to multiple testing. J R Stat Soc B 57:289-300

59. Dimonte S, Mercurio F, Svicher V, D'Arrigo R, Perno CF, Ceccherini-Silberstein F (2011) Selected amino acid mutations in HIV-1 B subtype gp41 are Associated with Specific gp120V3 signatures in the regulation of co-receptor usage. Retrovirology $8: 33$

60. Svicher V, Aquaro S, D'Arrigo R, Artese A, Dimonte S, Alcaro S, Santoro MM, Di PG, Caputo SL, Bellagamba R, Zaccarelli M, Visco-Comandini U, Antinori A, Narciso P, Ceccherini-Silberstein F, Perno CF (2008) Specific enfuvirtide-associated mutational pathways in HIV-1 Gp41 are significantly correlated with an increase in $\mathrm{CD} 4(+)$ cell count, despite virological failure. J Infect Dis 197:1408-1418

61. Svicher V, Alteri C, D'Arrigo R, Lagana A, Trignetti M, Lo CS, Callegaro AP, Maggiolo F, Mazzotta F, Ferro A, Dimonte S, Aquaro S, Di PG, Bonora S, Tommasi C, Trotta MP, Narciso P, 
Antinori A, Perno CF, Ceccherini-Silberstein F (2009) Treatment with the fusion inhibitor enfuvirtide influences the appearance of mutations in the human immunodeficiency virus type 1 regulatory protein rev. Antimicrob Agents Chemother 53:2816-2823

62. Larrouy L, Lambert-Niclot S, Charpentier C, Fourati S, Visseaux B, Soulie C, Wirden M, Katlama C, Yeni P, Brun-Vezinet F, Calvez V, Marcelin AG, Descamps D (2011) Positive impact of HIV-1 gag cleavage site mutations on the virological response to darunavir boosted with ritonavir. Antimicrob Agents Chemother 55:1754-1757

63. Leal E, Janini M, Diaz RS (2007) Selective pressures of human immunodeficiency virus type 1 (HIV-1) during pediatric infection. Infect Genet Evol 7:694-707

64. Lemey P, Kosakovsky Pond SL, Drummond AJ, Pybus OG, Shapiro B, Barroso H, Taveira N, Rambaut A (2007) Synonymous substitution rates predict HIV disease progression as a result of underlying replication dynamics. PLoS Comput Biol 3:e29

65. Shankarappa R, Margolick JB, Gange SJ, Rodrigo AG, Upchurch D, Farzadegan H, Gupta P, Rinaldo CR, Learn GH, He X, Huang
XL, Mullins JI (1999) Consistent viral evolutionary changes associated with the progression of human immunodeficiency virus type 1 infection. J Virol 73:10489-10502

66. Yang W, Bielawski JP, Yang Z (2003) Widespread adaptive evolution in the human immunodeficiency virus type 1 genome. J Mol Evol 57:212-221

67. Isaka Y, Sato A, Miki S, Kawauchi S, Sakaida H, Hori T, Uchiyama T, Adachi A, Hayami M, Fujiwara T, Yoshie O (1999) Small amino acid changes in the V3 loop of human immunodeficiency virus type 2 determines the coreceptor usage for CXCR4 and CCR5. Virology 264:237-243

68. Santos-Costa Q, Parreira R, Moniz-Pereira J, Azevedo-Pereira JM (2009) Molecular characterization of the env gene of two CCR5/CXCR4-independent human immunodeficiency 2 primary isolates. J Med Virol 81:1869-1881

69. Santos-Costa Q, Mansinho K, Moniz-Pereira J, Azevedo-Pereira JM (2009) Characterization of HIV-2 chimeric viruses unable to use CCR5 and CXCR4 coreceptors. Virus Res 142:41-50 